\title{
Métodos e procedimentos utilizados na educação especial na perspectiva da educação inclusiva
}

\section{Methods and procedures used in special education in the perspective of inclusive education}

Ariane Martins dos Santos é psicóloga, graduada pelo Centro Universitário do Leste de Minas Gerais - UNILESTE-MG.

Contato: arianeegandra@gmail.com.

Maria do Rosário de Fátima Rodrigues é psicóloga, mestre em Psicologia, doutora em Psicologia pela Universidade Federal do Espírito Santo, professora do curso de Psicologia do Centro Universitário do Leste de Minas Gerais - UNILESTE-MG.

Contato: rosariopsi@uol.com.br.

\section{Resumo}

0 objetivo desta pesquisa foi conhecer os métodos e procedimentos utilizados na educação especial na perspectiva da educação inclusiva. Trata-se de um estudo de caso. Participaram oito professoras e um aluno com deficiência visual de uma classe do $7^{\circ}$ ano do ensino fundamental de uma instituição de ensino regular privada. Os dados foram obtidos por meio de entrevistas semiestruturadas realizadas com os professores e $o$ aluno participante, além de uma observação de cada disciplina. Os resultados evidenciaram a insuficiência de métodos e de procedimentos eficazes na inclusão desse aluno. Os profissionais da educação dessa instituição não se mostraram conhecedores dos recursos que podem utilizar para desenvolver um trabalho com os alunos com necessidades educativas especiais. Pôde-se perceber que o processo de inclusão se encontra ambivalente, pois é exposto e discutido na organização escolar, mas os 
indivíduos que fazem parte dessa instituição não a praticam por falta de conhecimento e insegurança.

Palavras-chave: métodos; procedimentos; inclusão escolar.

\begin{abstract}
The objective of this research was to understand the methods and procedures used in the special education in the perspective of inclusive education. It is a case study. Participants were eight teachers and a student with a visual impairment of a class of 7 th grade level of a regular private educational institution. The data were obtained through semi-structured interviews with the teachers and the participant student, through an observation of each discipline. The results showed the absence of efficient methods and procedures in the inclusion of this student. The education professionals of this institution did not show that they were knowledgeable of the resources they can use to develop a work with students with special educational needs. It could be seen that the process of inclusive is adversarial. The process of inclusion is ambivalent, because it is discussed in the school organization, but individuals who are part of the institution do not practice for lack of knowledge and insecurity.

Key-words: methods; procedures; school inclusion.
\end{abstract}

\title{
Introdução
}

A educação compreende os processos formativos que se constituem na vida familiar, na convivência humana, no trabalho, nas instituições de ensino, nos movimentos sociais e nas manifestações culturais. A educação é dever da família e do Estado, tem como referência os ideais de liberdade e solidariedade, como também o desenvolvimento completo (o exercício da cidadania e a qualificação para o trabalho) do educando (BRASIL, 1996).

A escola é o lugar privilegiado de transmissão do conhecimento formal. Nela se configuram os processos de produção e reprodução cultural. Dentre estes, salienta-se a contradição entre a inclusão e a exclusão. No que se refere aos sistemas de ensino, mesmo com a universalização do acesso a todos, ainda continuam 
sendo excluídos os indivíduos e grupos que são considerados fora do padrão comum da escola. Mesmo perante a perspectiva dos direitos humanos e da definição de cidadania, pautada no reconhecimento das diferenças e da diversidade, ocorre a regulação e produção das desigualdades. Esse movimento revela os processos comuns de discriminação dos alunos quanto às suas características intelectuais, físicas, culturais, sociais, enfim.

Na declaração mundial Educação Para Todos (1990), uma iniciativa da Unesco, foi proposta a universalização do acesso à educação de qualidade e a garantia da aprendizagem para todos. Entende-se que a educação é indispensável, pois pode contribuir para um mundo mais saudável, seguro e próspero, que também beneficie o progresso social, econômico e cultural. Assim sendo, todos os indivíduos devem ter acesso à educação, sem qualquer tipo de discriminação (WCEFA, 1990 apud PLETSCH; SILVA, 2010).

Em se tratando dos indivíduos com necessidades educativas especiais, a educação tem se destacado como um ambiente privilegiado para favorecer o processo de inclusão social, sendo o espaço escolar como mediador de uma escola para todos (BRASIL, 2003).

A educação inclusiva apresenta uma configuração de um modelo de instituição de ensino que seja adequado para acolher e educar todas as pessoas, sem qualquer distinção, independentemente de sua característica pessoal ou social. 0 movimento pela educação inclusiva surgiu decorrente de debates internacionais, no contexto da defesa dos direitos humanos (LOURENÇO, 2010).

No Brasil, a educação inclusiva começou a ganhar espaço na década de 1980, a partir da veiculação de dados surpreendentes sobre evasão e fracasso escolar e também com a crescente necessidade de criação de classes especiais. Nessa mesma década, as exigências das várias organizações da sociedade civil e associações de pessoas com necessidades especiais contribuíram para que a Constituição Federal de 1988 estabelecesse o modelo da educação para todos, por meio do qual as políticas educacionais passaram por intensas transformações (LIMA, 2006 apud LOURENÇO, 2010).

Especificamente nas discussões educacionais, a educação inclusiva tomou impulso legal a partir da Lei e Diretrizes e Bases da Educação Nacional, $n^{\circ} 9.394$ (BRASIL 1996). Essa lei orientou as Diretrizes Nacionais para a Educação Especial por meio da 
Resolução $\mathrm{n}^{\circ} 4$ do Conselho Nacional de Educação/Câmara de Educação Básica (BRASIL, 2009).

A discussão sobre a inclusão de indivíduos com necessidades especiais no âmbito da educação teve maior ênfase na década de 1990, a partir da Declaração Salamanca (1994), considerada um referencial sobre a escolarização de alunos nesta condição.

A Conferência Mundial sobre Necessidades Educacionais Especiais de 1994 postulou a obrigatoriedade das escolas receberem todas as crianças, independentemente de sua condição pessoal, intelectual, física, social, entre outras (UNESCO, 1994). Nessa conferência foi elaborada a Declaração de Salamanca, na qual anuncia as políticas e práticas na área das necessidades educativas especiais. Segundo Silva (2009), esse documento contribuiu decisivamente para criar perspectivas no que se refere à educação de todos os alunos em termos de suas potencialidades e capacidades, além de orientar a elaboração de currículos e estratégias pedagógicas adequadas para facilitar a organização escolar diante a inclusão.

A partir da Constituição Federal foi elaborada a Lei $\mathrm{n}^{\circ}$ 9.394/1996 de Diretrizes e Bases da Educação Nacional (LDBEN), na qual foram elaborados planos, programas e projetos voltados para a educação inclusiva.

O Plano Nacional de Educação apresenta diretrizes, metas e estratégicas de concretização para todos os níveis, modalidades e etapas educacionais. Este estipula estratégias específicas para a inclusão de alunos com deficiência, indígenas, quilombolas, estudantes do campo e alunos em regime de liberdade assistida. A universalização e ampliação do acesso à educação em todos os níveis educacionais, o incentivo à formação de professores e profissionais da educação, avaliação e acompanhamento diário e individualizado de todos os envolvidos na educação são algumas das metas desse plano (BRASIL, 2010).

Dentre os programas aprovados no Brasil, no que se refere à educação inclusiva, está o projeto "Educar na Diversidade", que tem o objetivo de contribuir para a melhoria da qualidade do ensino e para a igualdade na educação através das escolas inclusivas e da formação dos professores, para que esses superem barreiras em relação à aprendizagem e possibilitem a inclusão educacional dos alunos. A Rede de Educação para a diversidade tem como objetivo distribuir e desenvolver metodologias educacionais para a inserção dos temas sobre a diversidade no dia a dia das salas de aula (LOURENÇO, 2010). 
De acordo com o projeto Educar na Diversidade (BRASIL, 2006 b), para que as escolas possam seguir avançando rumo à educação inclusiva, são necessárias que sejam criadas condições favoráveis à inserção dos alunos. Os resultados favoráveis dessa inserção dependem de fatores como a aceitação das diferenças. A experiência diz que as escolas que conseguem bons resultados com todos os seus alunos caracterizam-se por: possuírem modos de aceitação e valorização da diversidade por parte de todos os pertencentes da área da educação; terem um plano educacional institucional que admite a atenção à diversidade; colocarem em evidência a presença de liderança e comprometimento, pela direção da escola; apresentarem adequação no processo de formação dos professores, no que se refere às necessidades educacionais especiais e também nas estratégias de atendimento à diversidade; possuírem modo de ensino acessível e flexível, aperfeiçoando as metodologias ativas e variadas, nas quais se permite a personalização dos conteúdos de aprendizagem a fim de promover alto grau de interação e participação de todos os alunos; incluírem métodos e procedimentos flexíveis de avaliação e promoção; aumentarem uma cultura de contribuição e colaboração entre pais, professores e alunos; proporem a participação ativa dos chefes de família; fornecerem serviços constantes de apoio para professores, alunos e pais; desenvolverem ações de colaboração e troca de experiências com outras escolas comuns e especiais da comunidade e por possuírem abertura e afinidade de colaboração com outros setores da comunidade.

Alvarez e Soler (1998), citados em Brasil (2006b), trazem algumas ideias básicas sobre a educação inclusiva e apontam alguns princípios no atendimento aos alunos com necessidades especiais, tais como: ter como fator principal o fato de que os indivíduos são diferentes e que a escola deve ajudar a cada aluno a desenvolver suas potencialidades livre de quaisquer rotulações ou seleções; eliminar a competitividade; proporcionar oportunidades para todos, colocando em evidência que todos são diferentes e que a educação não formará sujeitos iguais; personalização em vez de padronização - ou seja, devem-se reconhecer as diferenças individuais, culturais e sociais do aluno e, por fim, é necessário respostas diversificadas para que se possam apropriar os métodos de aprendizagem nas diversas ocasiões. 0 movimento em direção à educação inclusiva se caracteriza como um novo aspecto da educação para todos, no qual a diversidade deve ser vista como um elemento importante do desenvolvimento social e pessoal. Portanto, para que a educação de qualidade para todos aconteça é necessária a transformação dos espaços 
educativos, no que se refere a sua organização, funcionamento e práticas (BRASIL, 2006b).

A educação inclusiva não significa considerar o aluno com necessidades especiais como normal, mas sim propor práticas, ou seja, atividades e procedimentos individualizados por meio dos quais o aluno dê conta de realizar e aprender (RODRIGUES; MOREIRA; LERNER, 2012). Assim, a inclusão do aluno com necessidades especiais em escolas regulares inclui a oferta de métodos e procedimentos de ensino que proporcionem a participação desses alunos nas atividades sociais e pedagógicas.

A educação do aluno com necessidades educativas especiais implica a passagem de uma pedagogia terapêutica, que se centra nos déficits dos alunos, para uma pedagogia criativamente positiva, ou seja, uma pedagogia que visa o desenvolvimento do aluno, que investe nas suas possibilidades. Em vez de se centrar a atenção no déficit que limita o desenvolvimento, a atenção é focalizada nas formas como o ambiente social e cultural podem mediar relações significativas para que as pessoas com necessidades educativas especiais tenham acesso à aprendizagem (COSTA, 2006).

A política de educação especial que orienta os sistemas de ensino para garantir o acesso de todos os indivíduos nas escolas regulares atendendo as suas necessidades educativas especiais compreende os fundamentos da educação inclusiva (BRASIL, 2006a). 0 atual conjunto de leis sobre a educação recomenda que as instituições de ensino devem garantir aos alunos com Necessidades Educacionais Especiais: métodos, procedimentos e uma organização específica para atender às suas necessidades (BRASIL, 2007).

No material de formação docente "Educar na Diversidade" do Ministério da Educação da Secretaria da Educação Especial, os autores Booth e Ainscow (2000), citados por Brasil (2006b), apontam um conjunto de características que deveriam ser levados em consideração para se progredir nos métodos e procedimentos da educação inclusiva, como: os conteúdos das aulas devem ser acessíveis e atender as necessidades, interesse e modos de aprender de cada aluno; a necessidade de promover atividades que retrate as diferenças, bem como a sua compreensão e aceitação; favorecimento da participação ativa dos alunos nas atividades; a realização de atividades que estimulem a cooperação entre os alunos; o incentivo à participação dos alunos nas aulas e o incentivo à aprendizagem dos alunos. 
Assim, segundo Brasil (2006b), para que se possa progredir no contexto da educação inclusiva é preciso que as escolas criem diversos métodos para facilitar o acontecimento de uma educação para todos. Diante disso, as escolas que conseguem chegar bem próximas ao ideal de uma educação inclusiva se caracterizam por: possuírem comportamentos de aceitação e valoração por parte da equipe escolar em relação a diversidades; terem um projeto político pedagógico que dê importância à diversidade; confirmarem a postura de liderança da direção da escola em relação à aprendizagem de todos os alunos; desenvolverem atividades que promovam a aceitação e compreensão das diferenças; estimularem a participação dos responsáveis pelos alunos no seu processo acadêmico; promoverem atividades que favoreçam a cooperação dos alunos; incentivarem os professores a incentivarem seus alunos e favorecerem a participação de todos os alunos em atividades fora da sala de aula.

A Sala de Recursos é um método previsto na educação especial. Para Mazzotta, (1982), conforme Baptista (2011), a sala de recursos funciona como auxilio à educação especial. Consiste em uma sala da própria escola, com materiais específicos para a necessidade dos alunos. Essa sala tem como objetivo ajudar os alunos a desenvolver as suas dificuldades e se manter nas classes regulares. 0 professor dessa sala tem o papel de prestar atendimento ao aluno e de oferecer assistência e orientação aos demais profissionais da escola e aos familiares dos alunos. Desse modo, com a proposta da Sala de Recursos na escola, o aluno com necessidades especiais é matriculado na classe regular de acordo com o seu nível de escolaridade e realiza um trabalho paralelo, individualizado e especializado neste outro ambiente.

O Ministério da Educação, juntamente com a Secretaria de Educação Especial, com o objetivo de ampliar a educação dos alunos com deficiência visual, apresentam o método Soroban (contador mecânico japonês e aparelho usado pelos deficientes visuais para cálculos). O Soroban contribui para o desenvolvimento do entendimento e estimula as habilidades mentais. Para a utilização desse aparelho é necessário que o aluno tenha uma compreensão dos conceitos de numerais e das bases lógicas de numeral decimal (BRASIL, 2000).

0 braile é o método mais conhecido para ser utilizado pelos indivíduos com deficiência visual. Trata-se de um método de leitura e escrita para cegos e é explorado pelo tato através de pontos em relevo. É composto por um conjunto de seis pontos, permitindo sessenta e três combinações diferentes que obtém 
todos os sinais necessários para a escrita. Esse método pode ser escrito com o instrumento de conjunto manual de reglete e punção e a máquina de datilografia Perkins Braille (BRASIL, 2000).

O serviço de itinerância pode ser considerado um recurso que visa contribuir com a qualificação da educação inclusiva para alunos com deficiência visual. Para Rocha e Almeida (2008) o ensino itinerante é uma modalidade de apoio pedagógico, utilizado para complementar e suplementar os serviços da educação comum. Esse serviço é destinado à escola regular que não possui recursos para a inclusão. De acordo com as especificidades legais desse ensino, existe somente a obrigatoriedade de se constituir junto com a coordenação da instituição de ensino um lugar para que se possam atender as necessidades específicas desses alunos com deficiência.

Os autores Toledo e Vitaliano (2012) apresentam o procedimento de Monitoria, no qual os alunos que estão adiantados na realização de suas atividades ajudam os colegas que têm dificuldade. Outro procedimento é o trabalho em grupo, no qual cada aluno realiza uma atividade que possui mais habilidade, e assim todos podem realizar as tarefas juntos, com colaboração. Por fim, os jogos também representam um importante instrumento de socialização e cognição.

As instituições de ensino que utilizam métodos e procedimentos específicos para o aprendizado do aluno, e que esperam um resultado eficaz, devem focalizar o desenvolvimento dos alunos, além de perceber a interação do aluno nas diversas situações para que se possa dar significado a esse processo.

Os métodos e procedimentos para os alunos com necessidades educacionais especiais ainda é de qualidade questionável. Isso dificulta o processo de aprendizado do aluno, acabando por deixá-lo em um lugar inferior em relação aos demais, e inferior em relação ao seu próprio processo de aprendizagem. Portanto, os métodos e procedimentos destinados a esses alunos ainda são deficientes; a maioria deles apresenta baixa preocupação com o processo de aprendizagem. Sobre esse aspecto, o que realmente é importante passa a ser o produto, em detrimento do processo (SILVA, 1997 apud NUNES; BRAUN; WALTER, 2011).

Assim, tendo em vista as especificidades dos métodos e procedimentos para as pessoas com necessidades educacionais especiais, no contexto inclusivo, pergunta-se: quais os métodos e procedimentos utilizados na educação inclusiva em uma instituição de ensino regular? 
Esta pesquisa teve como objetivo geral, conhecer os métodos e procedimentos utilizados na educação especial na perspectiva da educação inclusiva. Como objetivos específicos, buscouse caracterizar a educação inclusiva; apresentar a legislação pertinente; conhecer os métodos utilizados e descrever os procedimentos utilizados pela Instituição.

\section{Metodologia}

\subsection{Tipo de Pesquisa}

Esta pesquisa se caracteriza como uma pesquisa exploratória de natureza descritiva, pois conforme Gil (2002) tem o objetivo de proporcionar maior familiaridade com o problema, a fim de tornálo mais claro. A pesquisa descritiva é aquela que busca conhecer e interpretar a realidade, bem como descrevê-la (CAMPOS, 2008 apud OLIVA, 2011).

\subsection{Participantes}

Essa pesquisa foi realizada em uma turma do $7^{\circ}$ ano do ensino fundamental de uma escola regular. Participaram dessa pesquisa o aluno com deficiência visual L.B.A, com 13 anos de idade, e os professores de português, inglês, matemática, ciências, geografia, história, educação física e ensino religioso.

Todas as professoras são do sexo feminino e possuem entre 33 e 50 anos de idade. As professoras têm de sete a 22 anos de formação acadêmica. Quanto ao tempo que atuam como professoras, varia de sete a 26 anos. No que se refere ao tempo de atuação com alunos em situação de inclusão, esse tempo vai de um a 20 anos.

\subsection{Instrumentos}

Para a coleta dos dados dessa pesquisa foi utilizado um roteiro de entrevista semiestruturada para os educadores, e outro para o aluno. Foi utilizada também uma grade de observação direta das aulas de cada disciplina, conforme Oliva (2011).

\subsection{Procedimentos}

As entrevistas foram aplicadas individualmente, fora do horário de aula, na própria escola. Quanto às observações, as aulas na 
escola observada têm 50 minutos de duração nas disciplinas de português, matemática, educação física, geografia, história, ciências, ensino religioso e inglês. 0 tempo de observação em sala de aula foi dividido em três semanas, sendo uma semana antes do período de férias e as outras duas semanas após o período de férias.

\subsection{Tratamento dos Dados}

As observações foram avaliadas qualitativamente, de acordo com os tópicos do roteiro da observação e dos dados observados, conforme Oliva (2011).

As entrevistas foram analisadas a partir da técnica de análise de conteúdo, segundo Bardin (1977), que se constitui por um conjunto de técnicas utilizadas na análise de dados qualitativos.

Cada instrumento foi analisado e interpretado individualmente. Após a análise individual, foi realizada a comparação dos resultados e uma análise geral, buscando uma compreensão qualitativa dos resultados.

\subsection{Cuidados Éticos}

Foram assinados os Termos de Consentimento Livre e Esclarecido como consta nas resoluções n 196/1996 e 466/2012. 0 primeiro contato com os professores, acompanhante e o aluno participante foi feito na sala dos professores e na sala de aula, no qual foi assinado o termo de consentimento e agendado o melhor dia e horário para as entrevistas. Todos foram informados de que se tratava de um trabalho acadêmico e que na divulgação dos resultados, a identidade deles seria preservada.

\section{Resultados e Discussão}

Os resultados das entrevistas realizadas com as professoras foram organizados nas seguintes categorias:

1. Inclusão escolar.

2. Aplicação dos métodos e procedimentos.

Para os resultados da entrevista realizada com o aluno, foi organizada a categoria: Sentimentos do aluno com deficiência visual. 
Em relação à percepção das professoras sobre a inclusão escolar, das oito entrevistadas, seis consideram a educação inclusiva como necessária e importante para o desenvolvimento dos alunos com necessidades educativas especiais. As professoras disseram que não é fácil conseguir trabalhar com os alunos que possuem alguma deficiência devido às turmas com muitos alunos.

Duas professoras relataram que, na prática, a inclusão não funciona. Segundo uma delas, a inclusão é bonita no papel, mas poucas escolas praticam.

Eu acho que na prática ela não acontece (silêncio)... Fica muito fácil incluir quando você tem dinheiro [...] Pra ele ter uma boa resposta ele precisa de uma escola que esteja preparada pra ele, a nossa escola ta preparada pra ele? Beleza. Mas ele precisa ter além da professora da sala de aula, ele tem que ter uma ajudante, isso tem que pagar. Você precisa, em casa ter uma pessoa pra ajudá-lo, em casa, e isso também custa dinheiro [...] Tudo isso hoje, eu acho que tá muito fora da realidade da maior parte das pessoas aqui dentro do Brasil. Por que ter dinheiro pra bancar isso tudo não é fácil [...] (professora 8).

Nos relatos das professoras sobre a inclusão, a maioria demonstrou preocupação com o resultado da inclusão. Elas relataram que a inclusão é necessária, mas que falta capacitação e apoio por parte da instituição. Pode-se dizer que as professoras veem a inclusão como algo favorável para o desenvolvimento do aluno com necessidades educativas especiais, mas esperam que a instituição lhes diga o quê e como fazer, para se promover uma inclusão satisfatória.

Conforme as professoras, falta preparação da instituição e, com isso, elas mesmas precisam criar procedimentos que atendam os alunos com deficiência. A ausência de recursos por parte da instituição faz com que as professoras se sintam confusas quanto a sua atuação com o aluno deficiente. Elas possuem algum conhecimento relacionado à inclusão, mas não sabem, ao certo, como realizá-la.

[...] ninguém sabe muito como ajudar, a gente faz tentando, errando, acertando. A gente tem poucos recursos, pouca ajuda. Tem hora que a gente fica um pouco perdido (professora 3 ).

Em relação a esse apoio, é oportuno citar o projeto Educar na Diversidade (BRASIL, 2006b) que apresenta sugestões às instituições escolares, tais como possuir um plano educacional que 
admite atenção a diversidade e apresentar adequação no processo de formação dos professores no que se refere às necessidades educacionais especais. Ainda seria necessário fornecer serviços constantes de apoio para professores, alunos e pais e, por fim, desenvolver ações de colaboração e troca de experiências com escolas regulares e especiais. Nesse caso, as professoras esperam uma parceria institucional que, conforme o projeto, seria umas das possibilidades de favorecer o processo de inclusão, pois nesse projeto é descrito que o avanço na educação inclusiva requer condições favoráveis à inserção dos alunos.

De acordo com a percepção das professoras, para que a instituição pesquisada favoreça a inclusão, seria necessário mais conhecimento, treinamento para professores, materiais pedagógicos, recursos tecnológicos, livros em braile, mais tempo para planejar aulas, quando houvesse nesta um aluno com deficiência. Segundo uma das professoras, uma capacitação para o corpo docente é importante, pois elas têm aprendido, sozinhas e intuitivamente, procedimentos de aprendizagem para o aluno com deficiência. Assim, elas compartilham das ações propostas pela literatura (BRASIL, 2006b).

Outra professora teve uma percepção diferente das demais: relatou que é necessário um trabalho em conjunto de todos os membros da escola (funcionários e alunos); que todos estejam ali com o objetivo de proporcionar desenvolvimento para o aluno com deficiência e contribuir para o aprendizado desse aluno. Pelo visto, a percepção dessa professora já condiz com a necessidade de um trabalho coletivo por meio do qual as instâncias administrativa e acadêmica se complementem.

Especificamente sobre a inclusão escolar do aluno participante, na percepção de cinco professoras entrevistadas, o aluno com deficiência visual, principalmente no que se refere à aprendizagem, pode aprender muito mais do que muitos alunos que não tem deficiência nenhuma, conforme ilustrado abaixo:

\footnotetext{
[...] E não são provas com sacrifício não, a gente só cobra assim, na que de cá eu dou uma imagem, na deles eu tenho que descrever a imagem pra alguém ler para eles, mas na questão de aprendizagem eles aprendem muito mais do que muitos alunos que não tem deficiência nenhuma[...] (professora 6).
}

Duas professoras responderam que o aluno com deficiência visual está sendo incluído, em parte, somente em algumas situações, e apenas uma professora relatou que o aluno não está 
sendo incluído como deveria. Desse modo, a maior parte das professoras relatou que o aluno com deficiência visual é capaz de aprender e progredir, que muitas vezes ele compreende o conteúdo melhor do que algum aluno que não possui deficiência. Assim, mesmo que ele necessite de algum método ou procedimento individualizado, consegue aprender o conteúdo com mais eficácia do que muitos alunos sem deficiência.

Das professoras que responderam que o aluno só está incluído em algumas situações, elas disseram que quando conseguem adequar as suas aulas para que esse aluno participe, seja com a adaptação de uma atividade ou aulas com debates e discussões, ele está sendo incluído. Entretanto, quando essa adaptação não é possível por algum motivo, o aluno fica ocioso e excluído, à espera de alguma atividade que ele dê conta de realizar.

A professora que relatou que o aluno não está incluído de maneira alguma, diz também que ele não está sendo incluído da forma como necessita. Ela verbalizou que devido o fato de ter apenas uma aula por semana, não tem tempo de favorecer a inclusão desse aluno em sua aula, uma vez que é pouco tempo e muito conteúdo. Assim, o aluno com deficiência visual faz parte da turma, participa das aulas dessa professora mais passiva do que ativamente.

Ao considerarmos esse relato, observa-se que os alunos não condizentes com o padrão da escola, mesmo com a universalização do acesso de todos ao ensino, ainda continuam sendo excluídos. Assim, a exclusão desse aluno contraria a Declaração Mundial Educação Para Todos, pois esta propõe a universalização do acesso à educação de qualidade e garantia de aprendizagem para todos, sem qualquer tipo de discriminação (WCEFA, 1990 apud PLETSCH; SILVA, 2010).

Ainda sobre inclusão escolar, no que diz a respeito às expectativas das professoras diante do aluno com deficiência visual, comparado aos demais alunos, seis professoras disseram que não há diferença entre o aluno com deficiência e o aluno sem deficiência. Relataram que todos conseguem aprender 0 conteúdo, mesmo que de modo diferente, utilizando de recursos individualizados (máquina de escrever em braile, acompanhante, atividades), todos que querem aprender conseguem.

Duas professoras disseram que existem diferenças entre os alunos: que aqueles com necessidades educacionais especiais ficam em defasagem quando comparados aos demais alunos, que 
não conseguirão ficar equiparados aos outros, tanto na escola quanto no mercado de trabalho.

Entretanto, uma delas, ao mesmo tempo em que disse não haver diferença entre o aluno com deficiência e os demais, que todos conseguem progredir, trouxe um relato contraditório, pois também relatou que um deficiente visual nunca conseguiria ser um engenheiro.

[...] É muito raro, eu não conheço caso de um cego que seja um engenheiro, então essa habilidade, esses detalhes da exata é pra quem quer seguir essa profissão, né. Então eles precisam ter noção do conceito, agora essa, esse aprofundamento fica difícil. Não é só porque eles não cegos não, porque tem aluno que tem todos os sentidos e tudo não são hábeis pra determinados conteúdos, né (professora 1).

Em síntese, por meio da análise da categoria sobre inclusão escolar, a maior parte das professoras entrevistadas considera a educação inclusiva como sendo importante para o aluno com necessidades educacionais especiais. No entanto, pode-se perceber que apesar de considerar esse fator como importante, as professoras expressam a necessidade de mais conhecimento e materiais específicos para fazer parte dessa educação para todos. Entretanto, não conseguiram expor com clareza quais os tipos de conhecimentos de que necessitam para praticar a educação inclusiva. Pôde-se perceber também que as professoras expressam diversos sentimentos, às vezes contraditórios, em relação à educação inclusiva.

No que diz a respeito à segunda categoria, relativa à aplicação dos métodos e procedimentos, observou-se que não são utilizados métodos especiais com o aluno com deficiência visual. As professoras utilizam procedimentos que elas mesmas criam para facilitar o aprendizado desse aluno. Por exemplo: a maioria das professoras disse que fazem atividades orais, atividades que acompanham o planejamento da aula, mas com grau de dificuldade menor. Além disso, não utilizam vídeos e procuram ensinar de uma forma concreta para facilitar o aprendizado do aluno com deficiência visual.

Uma das professoras relatou um procedimento que utilizou para explicar uma aula:

0 que eu uso da minha experiência é na medida do possível, dentro da minha matéria, trabalhar o concreto. Ah, então, por 
exemplo, igual lá agora, então eu to estudando grupo seres vivos, então o molusco que é uma minhoca, ai eu pego um barbante para eles verem, o anelídeo que é a minhoca eu trouxe um barbante cheio de macarrão pra mostrar os anéis, o molusco que é o copo mole, eu sugeri simplesmente uma geleia, então eu uso assim, tentar trabalhar com material concreto dentro do possível, mas treinamento pra isso e técnicas mais aprimoradas a gente não tem não, a gente tá aprendendo mesmo junto com eles (professora 6).

Nesse sentido, faz-se necessário que as escolas favoreçam a participação e a informação dos educadores no planejamento e aplicação de práticas curriculares inclusivas, para que possam favorecer condições de transformar a cultura escolar, valorizando o respeito à diversidade.

Todos os indivíduos são diferentes e a escola tem o papel de auxiliar cada aluno a desenvolver as suas potencialidades sem qualquer discriminação, além de proporcionar oportunidades para todos, colocando em evidência que todos são diferentes e que a educação não formará sujeitos iguais (ALVAREZ; SOLER, 1998 apud BRASIL, 2006b).

A aplicação dos métodos e procedimentos, para a acessibilidade do aluno com deficiência, requer planejamento prévio; o que, na ausência, pode ser utilizado como justificativa para a não realização. A falta de tempo no dia a dia das professoras é um desafio para a elaboração de planejamentos direcionados a esse aluno. Com essa ausência, as atividades são criadas no momento da sua realização. Assim, a carência de aplicação dos métodos e procedimentos para a acessibilidade desse aluno, no contexto escolar, resulta em exclusão. Mesmo que ele seja incluído na turma por parte dos colegas de classe, é excluído no que diz a respeito ao conteúdo, que geralmente é passado de forma superficial.

Para que se possa progredir no contexto da educação inclusiva, é preciso que as escolas criem diversos métodos para facilitar o acesso da educação para todos. Diante disso, as escolas que conseguem chegar bem próximas ao ideal de uma educação inclusiva se caracterizam por apresentarem comportamentos de aceitação por parte da equipe escolar; incentivo aos professores e alunos; participação de todos os alunos nas atividades, promoção de atividades que favoreçam a cooperação dos alunos (BRASIL, 2006b).

A educação inclusiva significa propor práticas individualizadas que o aluno dê conta de realizar e, com isso, se desenvolver (RODRIGUES; MOREIRA; LERNER, 2012). 
Alguns recursos, métodos e procedimentos foram expostos na introdução desta pesquisa, que podem ser utilizados no movimento da educação inclusiva, tais como: a Sala de Recursos; o Serviço de Itinerância; o Método Soroban; o procedimento de Monitoria e o recurso dos jogos.

Na presente pesquisa, as professoras expressaram desconhecimento acerca de recursos, métodos ou procedimentos que podem ser utilizados para o desenvolvimento educacional e pessoal do aluno com deficiência, uma vez que elas não mencionaram o uso de método e/ou procedimento preconizado nos planos oficiais.

Por fim, no que diz respeito à aplicação dos métodos $e$ procedimentos direcionados ao aluno com deficiência visual, como também outras deficiências, não foi possível descrever a sua qualidade, visto que os professores não os utilizam. Portanto, o aprendizado e o desenvolvimento do aluno com deficiência pode se tornar defasado.

A seguir, será apresentada a categoria sentimento do aluno com deficiência visual em relação à inclusão escolar. Sobre os sentimentos, ele relatou que se sente feliz em estudar na escola, que o seu relacionamento com os colegas e professores é muito bom. Relatou também que aprende tudo o que o professor ensina e que está na escola para aprender o braile e fazer provas.

Durante a entrevista, o aluno expôs minimamente os seus sentimentos, suas falas foram bem curtas. Assim, relatou sobre o seu relacionamento com os colegas, professoras e escola, respectivamente:

\section{[...] São bons, são muito bons. É ótimo. \\ Muito feliz. Eu gosto de estudar aqui.}

No entanto, analisando a entrevista, juntamente com as observações realizadas em salas de aula, percebeu-se que o aluno se encontra, em alguns momentos, excluído. Por mais que ele considere ter um bom relacionamento com todos da comunidade escolar e apontar suas expectativas sobre a escola, L.B.A. parece não se sentir à vontade em sua sala de aula, com seus colegas de classe e professores, por mais que procure realizar com satisfação todas as atividades propostas pelos professores. Ele fica a maior parte do tempo sozinho, em silêncio e ocioso. Para que a inclusão desse aluno aconteça é necessária uma transformação 
na organização, no funcionamento e nas práticas dos espaços educativos.

Nesse sentido, ressalta-se a importância dos métodos e procedimentos que, como já citado, ainda são de qualidade questionável. Conforme Silva (1997 apud NUNES; BRAUN; WALTER, 2011), os métodos e procedimentos destinados para esses alunos ainda são deficitários, pois na maioria deles não se percebe promoção do processo de aprendizagem.

Em relação à aprendizagem desse aluno, provavelmente se houvesse o apoio de métodos e procedimentos adequados, ele não estaria tão isolado, silencioso e ocioso, pois os pressupostos do trabalho deveriam focar-se na interação, na atividade e no desenvolvimento da linguagem.

Visto as categorias das entrevistas, a seguir serão descritas as observações das aulas:

A aula de matemática foi destinada a um trabalho em grupo. A professora dividiu a turma em grupos de três e quatro alunos e o aluno com deficiência não foi incluído em nenhum grupo. 0 trabalho em grupo consistiu em um jogo de tabuleiro, no qual o objetivo foi a resolução e a aprendizagem de equações do segundo grau. Os demais alunos iniciaram a atividade. Um colega perguntou a professora se o aluno com deficiência não iria participar de nenhum grupo, ao que a professora respondeu que ele faria outra atividade. Logo após, a professora foi até a carteira do aluno com deficiência e passou para a acompanhante uma série de equações, sendo que essas foram com grau de dificuldade menor, comparadas às dos demais colegas da classe. As equações foram realizadas oralmente juntamente com a acompanhante.

Na segunda aula observada, de inglês, a professora entrou na sala e cumprimentou todos os alunos com um bom-dia. Nessa aula, o assunto foi família e um áudio em inglês foi utilizado como recurso de material para aprendizagem. Esse se tratava de um texto que havia no livro didático dos demais alunos, o áudio era passado enquanto a turma acompanhava em seus livros. Ressaltase que o aluno com deficiência não possuía o livro didático e a aula transcorreu normalmente para os demais os alunos, ficando o aluno com deficiência, mais uma vez, em silêncio, ocioso e fazendo movimentos repetitivos com cabeça e braços.

Após algum tempo que a aula havia iniciado, a professora se dirigiu para o aluno com deficiência, enquanto a turma realizava 
uma atividade, passou o áudio novamente e perguntou ao aluno o que ele havia entendido do áudio, que palavras ele havia ouvido e qual os significados delas em português. 0 aluno não soube responder, disse que não havia entendido nada do áudio. Antes que a professora realizasse uma intervenção, um colega interrompeu com uma pergunta sobre o dever de casa. Assim, a professora se posicionou para a correção do dever de casa e o aluno com deficiência permaneceu em sua carteira, ocioso. Foi perguntado ao aluno se ele havia realizado o dever, que consistia em trazer uma foto da sua família. Ele respondeu que havia esquecido.

Poucos minutos antes do término da aula, toda a turma já esperava o toque do sinal para trocar de disciplina; já era momento de descontração quando a professora foi até o aluno com deficiência e começou uma atividade oralmente, a qual consistia na professora falar palavras que faziam sentido sobre a matéria da aula, como pai, mãe, avô, avó, irmão..., ora em português ora em inglês para que o aluno pudesse dizer o significado das palavras ditas pela professora. Essa atividade se deu até o toque do sinal.

A aula de geografia foi destinada à continuação da aula anterior. A matéria foi sobre tipos de solos e clima. A professora passou a matéria no quadro e realizou perguntas sobre a matéria à turma, inclusive para o aluno com deficiência, que respondeu corretamente a pergunta feita pela professora. Os demais alunos e a professora o elogiaram e complementaram a sua resposta.

A aula seguiu com a professora escrevendo a matéria no quadro. Enquanto isso, o aluno permaneceu com a cabeça abaixada sobre a mesa. A professora chamou a sua atenção para que ele prestasse atenção na aula. 0 aluno ficou um tempo com a cabeça erguida, mas logo depois abaixou sobre a mesa novamente.

A professora passou uma leitura para a turma e sentou com o aluno com deficiência para explicar sobre o conteúdo do qual a turma estava lendo. A professora permaneceu alguns minutos com ele e depois passou o livro para a acompanhante, para que ela continuasse o trabalho.

A aula de história foi observada após o recreio. A acompanhante do aluno com deficiência saiu para lanchar e ele ficou em sua carteira ouvindo o movimento da turma. A professora iniciou a aula com um bom-dia e conduziu a explicação de uma nova matéria, passando no quadro o conteúdo. Toda a turma se encontrava em silêncio, copiando. 0 aluno com deficiência se encontrava debruçado na mesa, cochilando. A acompanhante chegou à sala 
depois de 30 minutos que a aula havia começado. Assim, o aluno com deficiência começou a digitar em sua máquina de escrever em braile o que estava no quadro com a ajuda da acompanhante, que ditava o que estava escrito no quadro.

$\mathrm{Na}$ quadra foram realizadas as aulas de ensino religioso e educação física. Na aula de ensino religioso foi realizada uma dinâmica, divididas em duas partes, a primeira com o movimento de todos os alunos em circulo e de pé e a segunda com o debate sobre a dinâmica. A dinâmica tinha o objetivo de trabalhar o equilíbrio e o sentimento de acolhimento do outro.

Todos os alunos participaram e o aluno com deficiência participou com a ajuda da acompanhante na primeira parte, pois necessitava do apoio dela para se movimentar. Na segunda parte, o aluno com deficiência participou sozinho dos debates sobre a dinâmica, interagindo com os demais colegas e a professora.

Outra aula realizada na quadra foi a de educação física. Nessa, o aluno com deficiência não participou: ficou sentado na arquibancada juntamente com a sua amiga, também deficiente visual e a acompanhante. Os três interagiram entre si. Os demais alunos estavam aprendendo handebol. No fim da aula, a professora orientou os alunos com deficiência para que trouxessem a bengala na próxima semana, para que a acompanhante realizasse voltas com eles ao redor da escola.

A aula de ciências iniciou com a correção do dever de casa oralmente e a acompanhante ajudou o aluno com deficiência. Após a correção, a professora passou uma atividade do livro didático para a turma. Entretanto, para o aluno com deficiência, ela passou um bloco de atividades, que para os demais colegas de classe seriam o dever de casa daquele dia. A professora disse para o aluno e a sua acompanhante que ele iria fazer a atividade do bloco, pois na do livro havia muita imagem e seria complicado para ele realizar. 0 aluno fez movimento afirmativo com a cabeça e iniciou a atividade com a ajuda da acompanhante, da maneira que ela lia em voz alta a pergunta e ele respondia oralmente. A acompanhante escrevia a resposta do aluno no bloco de atividade.

A última aula observada foi a de português. A professora iniciou a correção do dever de casa. 0 texto era sobre namoro na adolescência. Havia ocorrido um episódio na semana anterior, na aula de educação física, na qual o aluno com deficiência e sua amiga, também deficiente visual, se beijaram. 0 texto, juntamente com o caso ocorrido, causou tumulto na sala de aula. Em meio à 
agitação o aluno envolvido permaneceu calado, mas sorriu sem graça, diante de algumas falas dos colegas. A professora utilizou o episódio para exemplificar o texto, além de falar sobre as responsabilidades e consequências de um namoro na adolescência. A professora deu continuidade à correção, o aluno permaneceu em silêncio e imóvel em sua cadeira durante quase todo tempo da aula. Ele havia feito o dever de casa, mas quem corrigiu foi a acompanhante. Durante a correção, a professora fez uma pergunta ao aluno com deficiência, que respondeu corretamente, quando os demais alunos o elogiaram.

Nas observações realizadas na sala de aula, o aluno se sentava na primeira fileira do lado direito da sala de aula, ao lado da porta, junto com outra aluna, que também tem deficiência visual, em uma mesa grande, igual a que é utilizada pelos professores. A acompanhante se sentava sempre ao seu lado. A mesa dele estava disposta de forma que ele ficava sentado de lado para o quadro e o professor, e de frente para toda a turma. 0 aluno ficava a maior parte do tempo em silêncio; ora de cabeça baixa, ora fazendo movimentos repetitivos com as mãos. Nas aulas expositivas, ele costumava seguir, com a ajuda da acompanhante, as anotações que eram feitas no quadro pelo professor. A acompanhante ditava e ele escrevia em uma máquina de escrever em braile (máquina Perkins Brailler).

0 aluno não interagia com os colegas ou professores espontaneamente. A sua participação se dava quando alguém Ihe dirigia a palavra. Ele interagia mais frequentemente com a acompanhante e sua colega de mesa. Costumava utilizar do discurso da amiga que sentava ao seu lado para fazer um comentário ou responder alguma pergunta a alguém. A interação dele com os colegas só acontecia dentro da sala de aula, uma vez que ele não participava do recreio como os outros alunos: ele lanchava dentro da sala de aula e permanecia lá até o término do recreio; no máximo, ia ao banheiro. Nenhum outro aluno tinha a autorização para ficar em sala na hora do recreio, enquanto os alunos com deficiência visual ficavam em sala juntamente com a acompanhante. As observações, no geral, não mostraram uma inclusão, uma vez que o aluno ficava a maior parte do tempo sozinho sem socializar-se com os demais colegas de turma.

Durante as observações pôde-se perceber que ele não demonstrava iniciativa para a participação durante as aulas e muito menos para a interação com as demais pessoas da escola. 0 aluno dependia da iniciativa do outro para que pudesse se manifestar. A sua fala, geralmente, era a resposta a alguma 
pergunta feita por alguém. Quando tinha dúvida ou necessitava de algo a sua fala era dirigida a sua acompanhante. Ele não demonstrava iniciar uma interação por si só; dependia do outro para ser inserido em algum processo de conversa, trabalho, brincadeira, atividade etc.

Sobre essas observações, é oportuno fazer referência à Declaração de Salamanca (1994), resultante de uma conferência mundial, por meio da qual foram anunciadas políticas e práticas referentes à educação inclusiva. A conferência postulou a obrigatoriedade das escolas receberem todas as crianças, independentemente de sua condição pessoal, intelectual, física, social, entre outras (UNESCO, 1994).

\section{Considerações finais}

Este trabalho teve como objetivo compreender os métodos e procedimentos utilizados na educação especial na perspectiva da educação inclusiva, bem como caracterizar a educação inclusiva, apresentar a legislação, conhecer os métodos utilizados e descrever os procedimentos utilizados pela instituição participante no aspecto da educação inclusiva.

A partir dessa pesquisa não foram encontrados métodos de ensino específicos para o aluno participante. Diante das entrevistas dos professores e das observações nas aulas, foram encontrados procedimentos de ensino direcionados a esse aluno, que muitas vezes são planejados no momento da aula. Os procedimentos encontrados podem ser considerados pouco elaborados, mas muitas vezes são o único modo que as professoras encontram para incluir tal aluno. Os procedimentos que as professoras relataram, como também aqueles observados pela pesquisadora, se baseiam nas adaptações de atividades e provas, ou seja, o assunto das atividades e/ou provas dos alunos sem deficiência são repassados para o aluno com deficiência com um grau de dificuldade bem menor.

Os profissionais da educação dessa instituição não se mostraram formalmente conhecedores dos recursos que poderiam utilizar para desenvolver um trabalho com os alunos com necessidades educativas especiais; sabem das existências de recursos, mas não buscam pelo conhecimento e aplicação dos mesmos.

Diante disso, considera-se que a instituição pesquisada não possui a compreensão dos recursos direcionados a educação 
inclusiva que existe, tornando, assim, uma prática de ensino/ aprendizagem excludente.

Diante disso, pôde-se perceber com essa pesquisa que o processo de inclusão se encontra em um momento contraditório. 0 processo de educação inclusiva é exposto e discutido na organização escolar, mas os indivíduos que fazem parte dessa organização não a praticam por falta de segurança e conhecimento.

A escassez de procedimentos e métodos específicos para a educação inclusiva de alunos com necessidades especiais foi uma das dificuldades desse trabalho. Outra dificuldade encontrada foi a falta de apoio de alguns pais de alunos com necessidades educacionais especiais para com essa pesquisa, uma vez que não permitiram que seu filho, que também estuda na mesma classe da instituição pesquisada, participasse da pesquisa. Diante disso, muitos dados significativos tiveram que ser omitidos em respeito aos cuidados éticos desta pesquisa.

Assim, sugere-se como continuação deste estudo a inclusão na amostra de mais escolas e participantes, principalmente considerando escolas nas quais a utilização de procedimentos e métodos estejam mais presentes no cotidiano dos professores e alunos.

Sugere-se, também, que os profissionais de psicologia, como também os profissionais da educação, ampliem o conhecimento sobre o tema, além de promover uma reflexão sobre as práticas dos métodos e procedimentos que podem ser utilizados na inclusão escolar de alunos com necessidades especiais.

Finalmente, foi observada a insuficiência de orientação e até mesmo de monitoramento, que são responsabilidades do Poder Executivo, faltando apoio para a instituição e para os profissionais que atuam com alunos com necessidades educativas especiais.

\title{
REFERÊNCIAS
}

\author{
BAPTISTA, Claudio Roberto. Ação pedagógica e educação \\ especial: a sala de recursos como prioridade na oferta de \\ serviços especializados. Revista Brasileira de Educação Especial. \\ [online]. 2011, v.17, n.spe1. Disponível em: <http://www.scielo. \\ br/scielo.php? pid=S1413-65382011000400006\&script $=$ sci_ \\ arttext> Acesso em: maio 2013.
}


BARDIN, L. (1977). Análise de conteúdo. São Paulo: Edições $70,2009$.

BRASIL. Ministério da Educação. Lei n.9.394, de 20 de dezembro de 1996. Lei de Diretrizes e Bases da Educação Nacional. Brasília, 1996. Disponível em: <http://www. planalto.gov.br/ccivil_03/LEIS/L9394.htm>. Acesso em: mar. 2013.

BRASIL. Ministério da Educação. Plano Nacional de Educação. Brasília, 2010. Disponível em: <http://portal.mec.gov.br/ index. php? option=com_content\&id=16478\&ltemid=1107 $>$. Acesso em: mar. 2013.

BRASIL. Ministério da Educação. Resolução CNE/CEB n ${ }^{0} 4$ de 02 de setembro de 2009. Resolução do Conselho Nacional de Educação e Câmara de Educação Básica. Brasília, 2009. Disponível em: <http://portal.mec.gov.br/dmdocuments/ rceb004_09.pdf>. Acesso em: mar.2013.

BRASIL. Ministério da Educação. Secretaria da Educação Especial. Subsídios para Gestão dos Sistemas Educacionais: Direito a Educação. Brasília, 2006a. Disponível em: <http:// portal.mec.gov.br/seesp/arquivos/pdf/direitoaeducacao. pdf $>$. Acesso em: mar. 2013.

BRASIL. Ministério da Educação. Secretaria da Educação Especial. Material de Formação Docente: Educar na Diversidade. Brasília, 2006b. Disponível em: <http://portal. mec.gov.br/seesp/arquivos/pdf/educarnadiversidade2006. pdf>. Acesso em: mar. 2013.

BRASIL. Ministério da Educação. Secretaria de Educação Especial. Atendimento Educacional Especializado: Deficiência Mental. Brasília, 2007. Disponível em: <http://portal.mec. gov.br/seesp/arquivos/pdf/aee_dm.pdf>. Acesso em: maio 2013.

BRASIL. Ministério da Educação. Secretaria de Educação a Distância. Deficiência Visual. GIL, Marta. (Org.). Brasília, 2000. Disponível em: <http://tvescola.mec.gov.br/images/ stories/publicacoes/cadernos_tv_escola/deficienciavisual. pdf $>$. Acesso em: maio 2013.

COSTA, Dóris Anita Freire. Superando limites: a contribuição de Vygotsky para a educação especial. Revista de Psicopedagia. [online], v.23, n.72, p. 232-240, 2006. ISSN 
0103-8486. Disponível em: < http://pepsic.bvsalud.org/ scielo.php?pid=S0103-84862006000300007\&script $=$ sci arttext>. Acesso em: abr. 2013.

GIL, A. C. L. Como elaborar projetos de pesquisa. 4 . ed. São Paulo: Atlas, 2002.

LOURENÇO, Érika. Conceitos e práticas para refletir sobre a educação inclusiva. Belo Horizonte, MG: Autêntica, 2010.

NUNES, Leila Regina d'Oliveira de Paula; BRAUN, Patrícia; WALTER, Cátia Crivelenti de Figueiredo. Procedimentos e recursos de ensino para o aluno com deficiência: o que tem sido disseminado nos trabalhos do GT 15 da ANPED sobre estes temas? Revista Brasileira de Educação Especial. [online], v.17, n.spe1, p. 23-40, 2011. ISSN 1413-6538.

Disponível em: <http://www.scielo.br/scielo.php?script=sci_ arttext\&pid=\$1413-65382011000400004\&lng=en\&nrm=iso\& tlng=pt>. Acesso em: mar.2013.

OLIVA, Diana Villac. A educação de pessoas com deficiência visual: inclusão escolar e preconceito. São Paulo: s.n, 2011. 244p. BR85.1 - USP/IP/SBD - LC1200 - 048e. Disponível em: <http://www.teses.usp.br/teses/disponiveis/47/47131/tde24052011-172502/publico/A_educacao_de_pessoas_com_ deficiencia_visual.pdf>. Acesso em: abr. 2013.

PLETSCH, Marcia Denise; SILVA, Isabelle Cristine Mendes da Silva. A Política de Educação Inclusiva no Ensino TécnicoProfissional: resultados de um estudo de caso. Revista Democratizar [online], v. IV, n.1., 2010. Disponível em: <http://www.eduinclusivapesquerj.pro.br/images/pdf/ Silva_Pletsch_Artigosemperiodicos_2010.pdf >. Acesso em: abr. 2013.

ROCHA, Margarette Matesco; ALMEIDA, Maria Amélia de. Ensino itinerante para deficientes visuais: um estudo exploratório. Revista Brasileira de Educação Especial. [online], v.14, n.2, pp. 201-216, 2008. ISSN 1413-6538. Disponível em: <http://www.scielo.br/scielo.php?script=sci_ arttext\&pid $=\$ 1413-65382008000200005>$. Acesso em: maio 2013.

RODRIGUES, Isabel. Barros; MOREIRA, Luiz Eduardo Vasconcelos; LERNER, Rogério. Análise Institucional do Discurso de professores de alunos diagnosticados como autistas em inclusão escolar. Psicologia: Teoria e Prática 
(Impresso), v. 14, p. 70-83, 2012. Disponível em: <http:// editorarevistas.mackenzie.br/index.php/ptp/article/ view/4356/3362>. Acesso em: mar.2013.

SAÚDE, Conselho Nacional. Resolução196/96 do Conselho Nacional de Saúde. Disponível em: <http://conselho.saude. gov.br/comissao/conep/resolucao.html>. Acesso em: maio 2013.

SILVA, Maria Odete Emyǵdio da. Da Exclusão à Inclusão: Concepções e Práticas. Revista Lusófona de Educação [online], n.13, pp. 135-153, 2009. ISSN 1645-7250.

Disponível em: <http://www.scielo.gpeari.mctes.pt/scielo. php? pid $=$ S1645 $-72502009000100009 \&$ script $=$ sci_arttext $>$. Acesso em: abr. 2013.

TOLEDO, Elizabete Humai de; VITALIANO, Célia Regina. Formação de professores por meio de pesquisa colaborativa com vistas à inclusão de alunos com deficiência intelectual. Revista Brasileira de Educação Especial, v. 18, n. 2, 2012. Disponível em:<http://www. scielo.br/scielo.php? pid=\$1413$65382012000200010 \&$ script $=$ sci_arttext $>$. Acesso em: maio 2013.

UNESCO. Declaração de Salamanca: sobre princípios, políticas e práticas na área das necessidades educativas especiais. Salamanca, 1994. Disponível em: <http://unesdoc. unesco.org/images/0013/001393/139394por.pdf>. Acesso em: mar. 2013.

UNESCO. Declaração Mundial sobre Educação para Todos: satisfação das necessidades básicas de aprendizagem. Jomtien, 1990. Disponível em: <http://unesdoc.unesco.org/ images/0008/000862/086291por.pdf>. Acesso em: abr. 2013.

UNESCO. Declaração Universal dos Direitos Humanos. Brasília, 1948. Disponível em: <http://unesdoc.unesco.org/ images/0013/001394/139423por.pdf>. Acesso em: ago. 2013.

Recebido em: 26/02/2014 Revisto em: 15/04/2014 Aprovado em: 16/04/2014 